\title{
What Angle Will You Take? Patterns of Perspective-Taking in a Body- Based Task
}

\author{
Tegan Garon \\ Department of Education, School of Education and Social Services, University of Vermont, Burlington, VT \\ Student: teags3@yahoo.com* \\ Mentor:carmen.smith@uvm.edu*
}

\begin{abstract}
When people conceptualize abstract ideas, different perspectives can help them to make connections and develop their reasoning. In this study, three third grade students who engaged in a body-based angle task, using the Kinect for Windows, were analyzed. Descriptions of their interviews are presented, including a detailed analysis of their patterns of perspective-taking and factors that might have been conducive to their learning. It was observed that students typically adopted a body-based perspective before transitioning to other perspectives. Further, the design of the task and interviewer comments were important factors that prompted students to take different perspectives. The implications for perspectives and their impacts on learning are discussed.
\end{abstract}

\section{KEYWORDS}

Embodied Cognition; Angles; Mathematics Education; Perspectives; Movement

\section{INTRODUCTION}

The act of learning mathematics necessitates a particular type of thinking, one in which a conceptual approach has been shown to be more useful than memorizing formulas and procedures. ${ }^{1}$ In order for students to develop conceptual understanding, mathematics instruction ought to scaffold students to make connections among concrete concepts, eventually resulting in the formation of abstract ideas.

Studies have shown that embodying concepts has become a new way for students to make meaning, since it promotes linkage between reasoning and physical movements, thus allowing students to connect seemingly unrelated ideas. ${ }^{2,3}$ Body-based activities can do more than allow students to relate ideas; they can actually help students to learn, particularly in mathematics. ${ }^{3,4}$ Learning occurs when a bridge is built between physical movements of a body and concepts stemming from cognition and reasoning. ${ }^{2}$ Body-based activities have been important in students' mathematical learning processes, 5,6 although a definitive relationship between embodiment and learning gains is still being explored by researchers and scholars. Nonetheless, body-based activities that seem conducive to learning are those that allow students to assume a first-person perspective while engaging in task. ${ }^{7,8}$

In this paper, we seek to investigate the conditions of body-based activities that support learning, including initially prompting students to take on the first-person perspective, and then providing access for them to advance to other perspectives. We will also consider the patterns of perspective-taking that three third grade students demonstrated while completing a body-based angle task using the Kinect for Windows.

\section{BACKGROUND}

Embodied cognition is a formal way of classifying how cognition and reasoning interact with the physical world around us. ${ }^{9}$ "Embodiment" is essentially a term that reflects how perceptual and motor skills play a prominent role in the formation of concepts. Reasoning and physical action are not separate activities; they are deeply integrated. ${ }^{10}$ Even thinking that requires the use of abstract concepts stems from embodied interactions with a physical environment. ${ }^{2}$ In general, body-based tasks serve as a means by which abstract mathematical ideas can be grounded in a form that is easily comprehensible and accessible for the learner. ${ }^{3}$ As a result, when students engage in body-based tasks, their understanding of abstract ideas can become more concrete, since their thinking is constructed from, as well as grounded in, physical actions. ${ }^{3}$

\section{Reasoning and Physical Interactions}

The assumption that reasoning and physical tasks are closely tied is not trivial. One might consider how it is possible for reasoning to "grow out of a cognitive task". ${ }^{10}$ Remarkably, several neural systems in the brain, those primarily responsible for perceptions, movement, and object manipulation, are the same neural systems that are utilized by the brain to achieve conceptualization and reasoning. ${ }^{10}$ Perception and reasoning always coincide with, and consequently, are structured by, a physical 
body's engagement with an environment. ${ }^{9}$ Sensory inputs that are acquired through physical experiences can be united into a cohesive entity that reflects how we manipulate and interact with the world around us.

The relationship between reasoning and embodiment is illustrated in a plausible, real-world example that many car owners, or car passengers for that matter, have surely experienced at one time or another. Michael Anderson presents the frustration of dropping a lifesaver (or similar bite-sized candy) in between the seats of a car and then realizing that there are no means by which to retrieve the lifesaver, other than using a stray paperclip. The paperclip will need to be manipulated into various positions in order to find the optimal shape that will hook the lifesaver, so through this trial-and-error experience, cognitive skills are forced to collaborate with physical capabilities. While transforming the paperclip into different positions, our mind must conceive how any given shape will be able to successfully hook the lifesaver. ${ }^{9}$ Embodied cognition requires cooperation between representation and physical movement, which exemplifies the interrelatedness between the two.

Whenever we engage in a physical task, our brains acquire a plethora of sensory inputs, stimulating the brain's perceptions that were activated during the task. The brain is able to later recall its cognitive state during the physical task; the inputs that were acquired have now become a representation of the physical activity. Therefore, when required to recall conceptual knowledge, people tend to draw upon those stored representations of the physical tasks. ${ }^{11}$ Research has shown that the greater number of sensory inputs triggered during a physical task will yield higher efficiency storage of schema since representations from the task can be recalled more easily. ${ }^{4} \mathrm{~A}$ strong ability to recall information often leads to high performance on assessment measures, which supports the position that body-based activities could result in learning gains.

In a study involving participants counting change with and without using their fingers, it was demonstrated how humans utilize cognitive resources to the best of their abilities, often relying on the assistance of physical actions. In the study, participants who were able to count by pointing to an image depicting a set of coins or counting with their fingers were more accurate than participants who were required to count the change without the assistance of their hands or fingers. ${ }^{12}$ Being able to call upon physical actions to help conceptualize ideas can result in the ability to solve larger and more complex problems. Reasoning is essentially a condensed version of knowledge that is acquired through interactions with the environment. ${ }^{1}$

In terms of embodied mathematics, a study was conducted in which students in grades 4-6 were tasked with turning a screen green by moving their hands to different positions, unaware that the screen only turned green when their hands were at a certain height above the desk, relative to each other. Eventually, students worked through the task with a Cartesian plane on the screen and continued utilizing the motion of their hands to determine how units on the plane were changing. ${ }^{13}$ In another study, participants were asked to justify mathematical tasks, such as a triangle side length conjecture, after completing various physical actions that were intended to promote either "character" (first-person) or "observer" (third-person) viewpoints. The results showed that physical actions enhanced mathematical justification, thus suggesting the linkage between embodiment and mental reasoning. ${ }^{14}$ Due to the close relationship between physical actions and cognition, we pose that body-based tasks help to shape the way we learn abstract mathematical concepts.

Perspectives During Body-Based Tasks

Body-based tasks are related to the ability for people to take on multiple perspectives during their interactions with a physical environment. ${ }^{15}$ Edith Ackermann terms the multiple perspectives that can be assumed during a body-based task as "diving in" and "stepping out". "Diving in" is referred to as completely immersing oneself in the task by "becoming one" with it, whereas "stepping out" involves reconsideration of the task from an outsider's perspective. ${ }^{5}$ Furthermore, learning can really only take place if we embrace multiple perspectives throughout the experience; one perspective is simply not enough. ${ }^{5}$ Ultimately, a balance between perspectives is ideal, since we need to immerse ourselves in the task in order for development and growth to take place, yet we must also become detached, at times, so that we can relate our thoughts to the physical task, resulting in reflection. ${ }^{5}$

Additional research has proposed that perceiving oneself as a part of the actual task may lead to greater success in solving the task. In one study, the use of perspectives was explored in a scientific setting as students engaged in a simulation called MEteor. The simulation consisted of a 30-foot by 10-foot interactive floor and prompted students to investigate Newton and Kepler's laws while viewing how their movements were affecting a graph on a screen. ${ }^{16}$ Students embodied a first-person perspective by seeing how their physical movements directly impacted the graph in front of them.

It is especially beneficial when problem solvers adopt more than one perspective. ${ }^{8}$ The multiple perspectives are described as "frames of reference", which can be generally categorized as either egocentric or allocentric. An egocentric perspective occurs when the objects/environment are in relation to one's self, resulting in short-term retention of knowledge, whereas an allocentric perspective occurs when the body is not the point of reference, and often leads to long-term retention. ${ }^{17}$ 
The multiple perspectives during a body-based task have also been termed as "being it", in which oneself is experienced as the mathematical object, and "watching it", in which a mathematical object is perceived to be separate from oneself. ${ }^{6}$ The ability to take on the first-person perspective is critical in mathematics since it leads to the formation of connections that cannot be made when a participant is exclusively an observer. ${ }^{6}$ Susan Gerofsky conducted a study in which students' and teachers' bodies were observed while they described a graph about an object in motion. Some of the participants took on the first-person perspective by demonstrating whole body movements as if they were the graphs themselves. These participants who "became the graph" were more likely than the other participants to approach their verbal explanations with multiple metaphors, thus suggesting that more than one entry point was used to make sense of the conceptual ideas of the graphs. ${ }^{7}$

Although a first-person perspective is optimal for immediate learning, a third-person perspective may yield greater long-term learning gains. ${ }^{17}$ When information acquired during a body-based task must be encoded, the body will most likely not be in the same context as it was during the task, which is why a third-person perspective becomes necessary for retrieval of stored information. ${ }^{17}$ Even when the third-person perspective has allowed for adequate retrieval of information, the first-person perspective becomes, again, necessary, so that people can continue to make sense of the task. ${ }^{17}$ Consequently, alternating between perspectives is the most useful in terms of storage, encoding, and retrieval of information.

The Angle Concept and Body-Based Angle Task (The Study)

The concept of an angle is often represented by various definitions and illustrations throughout textbooks; the teaching of angles is not always consistent across schools. ${ }^{18}$ For example, younger students learn about angles as being fractions of circles whose measure is converted into fractions of 360 degrees. ${ }^{19}$ They try to eventually reach a notion of a "standard angle concept", which is that two lines meet at a point. ${ }^{18}$ Other students learn angles as being inclinations of two lines in a plane. ${ }^{20}$ The main issue is that angles are typically introduced in a procedural sense, lacking the emphasis that they are units of measure in degrees. ${ }^{19}$

There are also numerous misconceptions that students perceive about angles. In one study, less than 10\% of fourth-grade students surveyed mentioned the "turning" feature when asked to describe angles, meaning that angles can be rotated in infinite orientations and their degree measure stays the same. ${ }^{21}$ Students may also believe that one of the rays of an angle must be horizontal, due to the limited examples they have been exposed to in textbooks. It is a common misconception that the size of an angle depends on upon the length of the line segments or the distance between the endpoints. Students' confusion could be alleviated if they were able to identify aspects of the angle concept within different representations, such as gestural, graphical, and verbal. $^{22}$

In this study, we analyzed three third grade students as they completed a body-based angle task. The task required students to physically form angles with their arms and then use their actions to create conjectures about angle properties. Since the concept of an angle is such a multifaceted entity, ${ }^{18}$ the task was designed to be particularly conducive to adapting multiple perspectives. Students might take on the first-person perspective by thinking of themselves as the angle (termed "body-based"), or they might take a third-person perspective, conceptualizing angles as abstract figures that are separate from their bodies (termed "anglebased"). Furthermore, as students translated between and coordinated the body-based and angle-based perspectives, they could also take on both perspectives simultaneously (termed “dual”).

We closely examined the language and actions of three students during their engagement with the body-based task to explore the following research questions: (1) What are possible patterns of perspective-taking during this body-based task? (2) What factors can affect students' abilities to take on different perspectives?

\section{METHOD}

Participants

This work was part of a larger study that included 32 third- and fourth-grade male and female students from four multi-age classes. Students ranged in age from eight to ten years. Each student took part in a 15-20 minute, structured, one-on-one interview with a researcher, ${ }^{23}$ in which they completed a body-based task about angle concepts. No compensation was exchanged for participation in the study, and participants were permitted to withdraw at any time. All interviews were videotaped, in an effort to relieve interviewers' responsibility of writing notes during interactions with participants. This project received approval from the Institutional Review Board.

Since this was an exploratory case study, ${ }^{24}$ we sought to find new patterns in the data. Stratified purpose sampling was used ${ }^{25}$ to select individual students' cases to investigate in depth. Using recorded video, transcripts, and interview notes, we examined the three students in detail, tracking their patterns of perspective-taking. The three students were selected due to their assessment scores on a pre- and post-test, in which one student earned high scores on both assessments, another student earned low scores on both assessments, and a third student earned a low score on the pre-test and a high score on the post-test. 


\section{Materials}

Each interview lasted approximately 40 minutes, which included 15-20 minutes for participants to work on the body-based angle task, and about 10 minutes each for the administration of a pre- and post-test. A Kinect sensor bar tracked participants' physical movements, so they stood facing a large screen that projected the Kinect program. The sensor bar located and used participants' base of their necks to form the vertex of an angle, and then their arms became the rays of the angle. Participants faced the Kinect sensor bar while an interviewer was positioned nearby. A second interviewer manipulated the various levels of the Kinect program on the Windows laptop.

\section{Procedure}

The body-based task was designed to support students' gradual development of an angle concept and to correct common misconceptions. For this reasoning, it was important to scaffold students' learning by first allowing them to explore the concept of an angle without the use of any tools or additional information, other than the notion that there was an angle on the screen. As students progressed through the activity, the lengths of the rays of the angle were increased, and then students were asked to explore how the size of an angle related to specific degree measures. Since the angle oriented itself to students' arms, students could also visualize how angles of the same measure could have different orientations. Furthermore, since the screen was constantly changing colors based upon the movements of students' arms, students were able to investigate what is meant by the size of an angle.
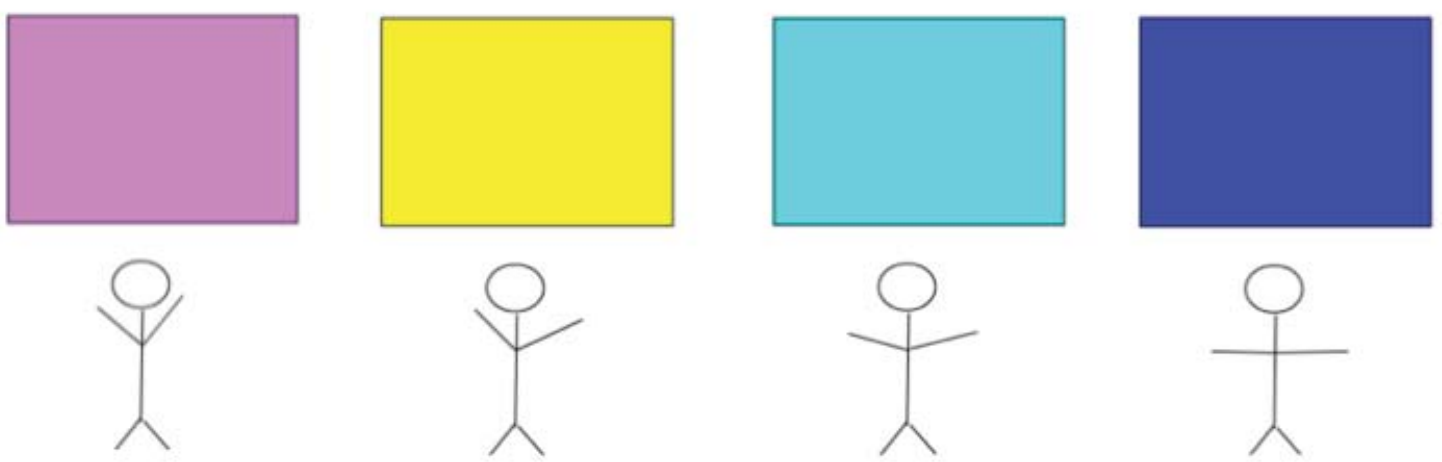

Figure 1. Representation of the four different types of angles in the body-based task with the corresponding colors of the screen.

At the start of the task, participants were instructed to extend their arms out to the side of their bodies, since the sensor bar could not track any movements if participants' arms were in front of or behind their bodies. Participants were informed that the screen in front of them would change colors, and they were asked to pose "rules" as to what made the screen each color. Unbeknownst to the participants, initially, were the conditions that changed the color of the screen: an acute angle changed the screen to pink, a right angle changed the screen to yellow, an obtuse angle changed the screen to light blue, and a straight angle changed the screen to dark blue (see Figure 1). The Kinect program was designed so that the screen changed colors for angles that were within an absolute value of three degrees from the actual measure. For example, even though a right angle, 90 degrees, caused the screen to be yellow, an angle measuring 87 to 93 degrees, inclusive, still activated the screen to be yellow. A similar pattern followed for the remaining three colors, although this information was not revealed to participants.

During the first part of the interview, participants were asked to describe what their arms were doing to make the screen different colors. The prompts were intended to be open-ended, so interviewer responses did not indicate whether participants' answers were correct or not. After participants posed conjectures as to how to make the screen each color, they were informed that a "tool" was going to be added to the screen: arrows. The vertex of the arrow matched to the base of participants' neck, and then the rays of the arrows tracked the movement of participants' arms, accordingly. For this portion of the task, participants were again asked to pose conjectures as to how to make the screen each of the four colors. If they only responded in a way that referenced the position of their arms, then the interviewer provided a follow-up question that prompted them to refer to the arrows on the screen.

In the third part of the task, a protractor was added to the screen, in which it automatically oriented itself with one of the rays of the angle and used the other ray to measure the angle, thus projecting a numerical value on the screen for participants to see. In 
addition to its projection of any numerical value from 0 to 180 degrees, inclusive, the protractor was labeled with benchmark numbers of $0,45,90,135$, and 180 degrees. At this time, participants were given approximately 30-45 seconds to experiment freely with the protractor while the interviewer left the room. Upon the interviewer's return, participants were asked whether they had figured anything out regarding how the protractor worked. Then, the interviewer proceeded to probe participants to form conjectures about how to make the screen each color, referencing the protractor in their responses, if possible.

For the final part of the task, the protractor remained on the screen and the length of the arrows was increased dramatically. Once it had been established with participants that the length of the arrows was different from the second and third parts of the task, participants were asked to form conjectures, one last time, about how to make the screen each color. The interviewer did not follow up with reinforcing questions and essentially accepted whatever response participants offered.

\section{Design and Coding}

Measures. Various forms of data were collected from each interview, including a pre- and post-test that was administered on an $\mathrm{iPad}$ as well as video recordings of the interview. The pre- and post-tests were completely identical and required students to sketch angles that were different from each other, sketch angles that were larger and smaller than given angles, sketch angles of designated measures, and estimate the measure of angles. Eleven total questions were scored, so participants could earn a whole number score, ranging from 0 to 11 on each of the tests. A 14-question spatial reasoning task was also included in both assessments, although that section of the assessment was excluded from the analysis of this study. The pre- and post-tests are described in another study. ${ }^{26}$

Coding. While implementing stratified purposeful sampling 25 in this study, we identified potential variation in the data between different types of students. All of the interviews were digitally recorded and transcribed so that student responses and interview prompts could be analyzed. We examined three students in depth. We present descriptions of the interviews in addition to an analysis of students' perspective-taking. These students were chosen based on their assessment scores: Jace performed well on both the pre- and post-test, Abdul received low scores on both the pre- and post-test, and Tony received a low pre-test score, but then improved greatly to earn a high post-test score.

Coding data is an act of stringing together the different parts of stories in order to make connections. ${ }^{27}$ Research suggests that grammatical realizations, i.e. language, can take two possible forms, based upon a participants' perspective: 1) private, first-person speech, in which participants refer to themselves as the experiencers of the task, and 2) public, third-person speech, in which participants do not make explicit references to themselves; instead, they narrate an account of the physical interactions with the object or environment. ${ }^{28}$ Through watching the interviews with participants, it became clear that their responses could be categorized into three perspectives. Based upon this first-level coding, the three pattern codes were established ${ }^{29}$ : body-based perspective, angle-based perspective, and dual perspective, respectively.

While it cannot be known for sure the various perspectives that participants were adopting, coding their language and gestures provide a strong indication as to how they were thinking and developing the angle concept. Multiple studies about embodied cognition have utilized coding in a similar manner in order to learn about participants' thinking. ${ }^{1,7,8,28}$ Participants' perspectives were coded as follows:

- Body-based perspective: Participants' verbal responses referenced their bodies, particularly the positions or movements of their arms. A common explanation that would be categorized as such might begin with, "My arms make the screen..." or, "I move my body to make the screen...".

- Angle-based perspective: Participants' verbal responses referenced the angle on the screen and the ways in which the positions and/or movements of the angle were being altered in order to change the screen's color. A common explanation that would be categorized as such might begin with, "The angle makes the screen..." or "The arrows change the color of the screen when...".

- Dual perspective: Participants' verbal responses referenced their body and the angle on the screen. A common explanation that would be categorized as such might begin with, "My arms move in this way which causes the angle to change the screen...". Furthermore, if a participant referenced the angle on the screen but was glancing at his/her body, a dual perspective was coded, since participants were focusing upon the angle while maintaining awareness of their bodily movements.

It has been demonstrated how gestures provide further means for analysis of perspective-taking during a body-based task. ${ }^{7,} 30 \mathrm{~A}$ first-person perspective incorporates the speaker's body into the gesture and sees the event as if s/he is the person performing the act, whereas a third-person perspective excludes the speaker's body from the gesture, so the hands act as the character as a whole. ${ }^{30}$ In this study, whenever participants looked at their body while speaking, it was implied that they had some awareness of their bodies, so their perspective was categorized as either body-based or dual. Additionally, participants' utterances were coded as 
being the dual perspective if they were describing an angle on the screen but were gesturing in a body-based fashion, such as pointing with their fingers to represent the arrows, moving their arms in a circular motion like the protractor, and/or continually glancing down at their bodies.

After each of participants' utterances were categorized as a body-focused, angle-focused, or body-and-angle-focused, all of the conditions that contributed to the first-level $\operatorname{codes}^{29}$ were analyzed using video recordings and transcripts of the interviews. The interviewer prompts were categorized as being (a) Scripted, deriving from the protocol, (b) Clarification, asking a student to clarify an idea, (c) Elaboration, asking a student to expand upon an idea, (d) Re-voice, repeating what the student said, or (e) Unprompted, the student offering a response without being prompted by the interviewer. Furthermore, the physical environment of the task was categorized according to the conditions of each stage, in which there was nothing on the screen during Stage 1, arrows in Stage 2, a protractor in Stage 3, and long arrows (with the protractor) in Stage 4.

\section{RESULTS}

\section{Case Studies}

Student 1: Jace

Jace, a nine-year-old boy in third grade, had never played with a Wii before, although he had used a Kinect. He did not have a Kinect at his house, however, so he did not use it frequently. For sports, Jace had participated in both dance and cheerleading and indicated that on a scale of 1 to $5(1=$ low, $5=$ high $)$, his preference towards mathematics was a 5 .

On the pre-test, Jace earned a score of 9. Despite his relatively high initial score, he still managed to improve by earning a score of 10 on the post-test. Because of Jace's high scores on both assessments, his interview was analyzed in order to gauge how students' thinking during the body-based task might enable them to achieve high scores.

During Stage 1 of the interview, Jace demonstrated a body-based perspective by consistently referencing the positions and movements of his body; there were not any angles on the screen, and the interview protocol directed participants to respond by referencing their bodies. Although Jace was not always initially correct with his contentions about how to make the screen each color, after moderate prompting from the interviewer, he was able to elaborate upon his responses and revise his original contentions. Jace quickly caught on to the sequence of colors and thought of his arms as lower and higher rungs on a ladder that would turn the screen each color. For example, to make the screen pink (an acute angle), Jace's arms needed to be placed low, whereas to make the screen dark blue (a straight angle), his arms needed to be high. Through this ladder metaphor, he was able to relate the sequence of colors to the positions of his arms.

During Stage 2 of the interview, when short arrows were added to the screen, a majority of Jace's responses shifted from being body-focused to angle-focused. This could partially have been attributed to the fact that the interview protocol no longer placed such a strong emphasis on bodily movements, like in the first stage. Jace expressed multiple metaphors as he grappled with how the angle was related to the color of the screen. When he was asked to make the screen pink (an acute angle), he explained how the angle looked like the top of a triangle, and then after the interviewer repeated his statement, he elaborated that the arrows looked like the top two lines of a triangle. When he was asked to make the screen yellow (a right angle), Jace thought that the angle looked like a normal pyramid, and that it looked like a bow when he was trying to make the screen light blue (an obtuse angle). When asked about dark blue (a straight angle), Jace returned to a body-based perspective by explaining how you have to "put your arm straight up" and then further noted how it "is just like a line", thereby returning to an angle-based perspective.

Stage 3 of the task, in which a protractor was added to the screen, supported Jace's development of the angle-based perspective. He quickly noted that in order to make the screen pink (an acute angle), the measure of the angle needed to be from 0 to 90 degrees. And then, without being prompted by the interviewer, Jace quickly and correctly listed the numerical degrees that described the other three types of angles and corresponding screen colors. Although he had temporarily abandoned a body-based perspective, he understood the "rules" for making the screen each color by correctly identifying the relationship between the color of the screen and angle measure.

Finally, Jace's perspectives were the least consistent during Stage 4 of the task, as he fluctuated between body-focused and anglefocused responses, and, several times, indicated body-and-angle-focused responses. In the following dialogue between Jace and the interviewer, he initially responds from an angle-based perspective, then shifts to a body-based perspective, and then briefly includes the dual perspective, by responding linguistically with an angle-focused response while simultaneously gesturing with his arms to represent the movement of the protractor:

Interviewer: And so let's look at yellow. What can you do to make yellow?

Jace: Go to 90.

Interviewer: $\quad$ Go to 90 ? 


Jace:
Interviewer:
Jace:
Interviewer:
Jace:

Yeah. You should go like this.

And when you say like this, what are you doing with your-

Putting one out.

Putting one out? Okay.

Because the other one just moves the scale [gestures the movement

of the protractor with his arms].

Jace was able to explore all three types of perspectives by responding to merely one color.

For the remaining questions of Stage 4, Jace alternated between an angle-based and body-based perspective by either referencing the degree measure of the angle, or the position of his arms. Even though he never fully embraced the dual perspective, it is clear that he was conscious of both perspectives, due to the ease with which he fluctuated from one to another during the last stage of the task, when the protocol prompts were relatively open-ended.

\section{Student 2: Abdul}

Abdul, a nine-year-old boy in third grade, had never used a Wii or Kinect before and did not own either of them at his house. He indicated that he played sports, and felt ambivalent about mathematics, as he rated it a 3, on a scale from 1 to 5.

On the pre-test, Abdul earned a score of 2 and did not demonstrate substantial learning gains as a result of the body-based task, since his score only increased to a 3 on the post-test. While Abdul might have acquired new knowledge by participating in the body-based task, such knowledge was not reflected in his minimal gain from pre- to post-test. Consequently, his patterns of perspective-taking become important for gaining insight as to why his test scores reflected little improvement.

During Stage 1 of the task, Abdul primarily explored a body-based perspective; his responses were nearly exclusively related to the movements and positions of his arms. As in the case with Jace, this type of response would be expected during the first stage, because the protocol questions prompt participants to consider how their bodies manipulate the screen's color. Additionally, there are not any angles on the screen for participants to reference. In general, during this stage and throughout much of the rest of the interview, Abdul was not particularly articulate and seemed to struggle with verbally expressing his ideas. His responses were often brief and lacked supporting detail and metaphor. Many of his responses during Stage 1 consisted of utterances such as, "Putting it straight", or, "The other arm", as well as others that were clearly body-focused but did not reveal a wealth of information regarding how he was thinking.

When the arrows were added to the screen for Stage 2 of the task, Abdul's perspective appeared to shift to being angle-based, since many of his responses exclusively referenced the angle. While Abdul was experimenting with making the screen light blue (an obtuse angle), the interviewer prompted him to elaborate on a brief response, and he included the metaphor, "They look like a clock." He later clarified that he meant the angle on the screen looked like a clock, although his clock metaphor was not referenced again at all during the remainder of the interview. Otherwise, during this stage, Abdul's responses continued to lack significant content, and while they were angle-focused in nature, they did not greatly reveal how he was thinking about the angles' impact on changing the screen each color.

Stage 3 of the body-based task included the addition of the protractor, and this did not encourage Abdul to make significant gains in correlating degree measures to the color of the screen. When asked how to make the screen pink (an acute angle), his response demonstrated the dual perspective, since he said, “...one hand is pointing in the middle of 60 and 45 and the other is just pointing at zero." By using his body to describe how to numerically change the angle, he was encapsulating both a body-based and anglebased perspective - in other words, the dual perspective. However, following this response, he retreated to replying with brief, nearly incomprehensible responses that either referenced solely his body or solely the angle. His responses that were anglefocused were not entirely correct, since, for example, he believed that making the screen yellow (a right angle) involved producing a 60-degree angle.

During Stage 4, the lengths of the arrows were increased, and Abdul articulated either body-focused or angle-focused responses, but never both. In fact, his responses hardly contained enough detail to be classified as having explored either perspective. For the last question, when he was asked to make the screen dark blue (a straight angle), he simply responded, "I don't know."

Student 3: Tony

Tony, an eight-year-old boy in third grade, had played with both a Wii and Kinect before, although he only had a Wii at his house. He indicated that he was regularly involved in sports, including swimming and biking, and expressed his dislike for mathematics by giving it a preference rating of 1 , on a scale from 1-5. 
On the pre-test, Tony earned a score of 4, and then notably improved to receive a score of 10 on the post-test. Tony's scores suggest that the body-based task was conducive to his learning and allowed him to demonstrate an improved understanding of elementary angle concepts.

In Stage 1 of the body-based task, Tony's responses were rich with a variety of metaphors that he was eager to explain and expand upon. As with Jace and Abdul's, Tony's responses during the first stage were entirely body-focused, as he continually referenced how his arms played a role in causing the screen to change each color. Tony's enthusiastic energy allowed for a rich dialogue between him and the interviewer, and he showcased his understanding through extensive verbalizations. When asked to make the screen pink (an acute angle), he believed that his body looked like a stick, and then immediately decided that a rocket was a more accurate depiction. By the time he was asked to contend how to make the screen yellow (a right angle), he developed the notion that he was making his arms into different forms of the letter T. For example, to make the screen yellow, he argued that he was "a sloppy T", whereas to make the screen light blue (an obtuse angle), he was "a higher T." By the time he was required to make the screen dark blue (a straight angle), he established that he was "just a T", and even corrected the interviewer when she asked if he was a sloppy T. "So, I never said sloppy T. I just said T," Tony remarked. His body-based perspective was extremely evident through this developed metaphor of the letter $\mathrm{T}$ that needed to be in various forms in order to change the screen each color.

The metaphors continued to develop during Stage 2 of the task, except, unlike Jace and Abdul, Tony remained in a body-based perspective, even though he still integrated many angle-focused responses. When asked how to make the screen yellow (a right angle), Tony referenced the hands of a clock and believed that making the arrows into the time of 4:35 enabled the screen to be yellow. For light blue (an obtuse angle), Tony thought that the angle looked like a bird flapping its wings. This is evidence of the vivid language Tony sought to articulate in his responses; rather than saying the angle looked like a bird, he developed the idea further that it was a bird in a specific stage of movement.

During Stage 3 of the task, Tony encapsulated both body-based and angle-based perspectives, thus resulting in the dual perspective. A true dual perspective means that a student is able to understand the connection between body and concept, or, in this case, the relationship between the movement of one's arms and the angle on the screen. The degree measures of the protractor were arguably vital in helping Tony to establish this connection between the two entities. Tony's ability to develop the dual perspective is evidenced by the following dialogue between him and the interviewer:

Interviewer: What can we do to make gold? (Note: The interviewer would always ask the participant what s/he wanted to call each color. In this particular interview, gold was equivalent to yellow, and violet was equivalent to dark blue.)

Tony: $\quad$ Make it so one hand is on zero and the other is on 90.

Interviewer: One's on zero, one's on 90?

[Unrelated conversation]

Interviewer: And what about light blue? What do you think of light blue?

Tony: Halfway between-put one arm at zero and the other arm between

90 degrees and 135 degrees.

Interviewer: $\quad$ Okay one arm to 135 degrees and 90 degrees. And what about dark blue_-violet. What do you do to make violet?

Tony: Violet is my friend. I think it's one hand on zero and the other hand's on 180 degrees. Just make a straight line.

Even though Tony's assertions were not always completely accurate (he was not entirely correct about the angle measure for light blue, for example), he still recognized the relationship between his arms and the angle on the screen.

While maintaining the dual perspective, Tony's metaphors continued into the final stage of the body-based task, although they were not nearly as elaborate as Stage 3. During Stage 4, Tony mentioned on several occasions that he was being asked the same questions multiple times, so perhaps he was becoming frustrated with the repetitiveness of the scripted questions, and did not feel the need to elaborate in as great detail. He answered nearly every question by explaining how one hand needed to be at a certain degree measure, and the other hand could either be within a range of degree measures or at a specific degree measure, depending upon the color of the screen that was being asked. It was clear during Tony's interview that he understood the interrelatedness between body and angle, and was able to assume multiple perspectives along the course of improving his learning.

\section{Analysis}

Overall, this body-based task did seem to support students' developing understanding of an angle concept. Out of all students (n $=32)$, the mean score increased from the pre-test $(\mathrm{M}=5.25, \mathrm{SD}=2.92)$ to the post-test $(\mathrm{M}=7.0, \mathrm{SD}=2.92)$. Based upon the descriptions of Jace, Abdul, and Tony's interviews, there is not one definitive pattern all students take as they complete the bodybased task. Their case studies detail different ways that students might be able to interact with the Kinect and try to make sense of 
the relationship between their body and the angle concept. To that end, there are several factors that became prominent throughout the interviews. It appears as if the physical environment, interviewer prompts, and use of metaphors are three factors that can affect students' abilities to assume different perspectives during this body-based task.

Physical environment. Overall, certain design decisions of the body-based task impacted the perspective that participants took. Participants essentially began with a blank slate, and then tools were progressively added to the screen. During the first stage, the screen was completely blank, aside from continually changing between the four colors. As illustrated in the three students' narratives, each of them began the task in a body-based perspective. Their responses consistently referenced the position and movement of their arms, and the notion of an angle was essentially nonexistent during this stage. It would almost seem illogical for participants to experience any perspective besides a body-based one during this part of the task since there were no tools whatsoever for them to reference. At this early point, it might not even have been clear to participants that angles were the overarching theme. Since all abstractness had been depleted and participants were left with a blank screen (in addition to their physical bodies), the environment limited the perspective. For this reason, coinciding with the scripted prompts, participants remained in a body-based perspective during the entire first stage of the task.

As each new stage of the task was reached, an additional tool was added to the screen, with the intention of allowing participants to utilize it in order to enhance understanding. Stage 3 was one of the most interesting parts of the interview in terms of the physical environment because a protractor was revealed. Prior to the interview, many participants admitted they did not know what a protractor was, had never used one before, or only had a vague idea of its capabilities. During Stage 3, after the interviewer explained how the protractor measures angles, participants were given about 30 seconds to freely explore with it, before being asked the standard questions again about how to make the screen each color. The interviewer just asked participants how to make the screen a certain color; there was no reference to the angle or to their bodies in the prompt. It became the responsibility of the student to internalize the purpose of the protractor and decide the manner in which s/he wanted to respond.

For Jace, a student who had already showcased his prior knowledge about angles on the pre-test, the addition of the protractor was useful in affirming his understanding of angles, since every response he offered was angle-focused. For the first time in the interview, he did not need to be prompted about how to make the screen each color, most likely since the protractor helped him to place a numerical value to the conceptual ideas that he had been developing during the previous two stages. The dialogue between Jace and the interviewer during Stage 3 proceeded as follows:
Interviewer:
Okay, so what can you do to make that pinkish-purple?
Jace:
It can be 45, so zero to-it keeps spinning.
Interviewer:
And if you bring your arms up in front of you now, if you bring it
back to the side?
Jace: It's from 90 to zero.
Interviewer: From 90 to zero.
Jace: And then yellow is only 90 .
Interviewer: Yellow is only 90?
Jace: $\quad$ Yeah, and then blue is from 90 to 180. And then purple is only 180

The interviewer did not prompt Jace in any way to respond from this perspective, so it can be deduced that the protractor was primarily responsible for Jace's angle-based perspective during this stage. Clearly, there were times during the interview when the environment was solely responsible for participants' perspective-taking.

Interviewer prompt. The protocol was designed with certain objectives in mind, one of which included scaffolding students to make connections between their bodies and the angle concept. Because of this, the verbal cues during each of the four stages were intentionally meant to prompt students to adopt different perspectives. Based on the aforementioned interviews, these prompts frequently played a role in the students' explorations of a particular perspective.

During Stage 1, there was an absence of tools on the screen and all of the questions were directly focused upon bodily movements, thus we expected participants to remain exclusively in a body-based perspective. During Stage 2, when the arrows were added to the screen, we expected participants to shift to an angle-based perspective, in hope that they would see the connection between body and angle. Therefore, much of the questions during Stage 2 were meant to prompt an angle-based perspective. The structure of the interview prompts seemed to play a role in Tony's development of the angle concept since he initially began Stage 2 by describing how the positions of his arms affected the color of the screen. However, because participants were supposed to shift their perspective during this stage, the interviewer posed questions to Tony that began to divert his attention away from his body and more towards the angle. The following conversation took place:

Interviewer: I'm going to ask you about pink again. What can you do to make it pink?

Tony:

I forget. Oh yeah. Be a-what some people call an airplane. 
Interviewer: What some people call an airplane? If you use the arrows on the screen, what are the-describe what's happening. What are the arrows doing?

Tony: The arrows are looking like-the arrows look like they're at their lowest position without just touching.

Interviewer: Okay. Lowest position without touching.

Without the interviewer prompting Tony to narrow his focus to the arrows on the screen, he may not have referred to them in his verbal responses, and could have potentially remained in a body-based perspective. Since Tony's scores on the pre- and post-tests increased so substantially, it is interesting to consider if his success can be attributed to the interviewer prompt, since it changed the perspective he had been experiencing.

Similarly, the same interview prompt at the identical stage in the task also seemed to help shift Jace's perspective. When he was first asked how to make the screen pink (after the arrows were added to the screen), he started to recall prior knowledge and thought that it was an acute angle. Although he was correct, classifying angles was not a desired learning outcome of the task, so in order to readjust his perspective to the angle itself rather than being an observer classifying an angle, a direct question about the angle on the screen was necessary. His focus was shifted and he assumed an angle-based perspective. Although there were surely other moments in the interviews when the scripted prompts played a role in maneuvering students' perspective-taking, the beginning of Stage 2 seemed to be the most pivotal for targeting students' thinking on a different perspective than what they had been grappling with just moments before.

Use of metaphor. The use of metaphors appears to support the development of the dual perspective. This was particularly evident in Tony's case. Compared to Jace and Abdul's, Tony's metaphors were much more frequent and tended to be articulated in far greater detail.

Stage 1 of Tony's interview included body-based metaphors that ranged from projectiles in motion to unique ways of writing letters. Tony's initial interaction with the Kinect was verbalized as such:

Interviewer: What do you do with your body to make that pink?

Tony: I'm just being a stick.

Interviewer: You're just being a stick? Is there another way you can make pink?

Tony: Being a stick. Being a rocket, I guess.

Interviewer: $\quad$ A rocket? Can you say more about that?

[Unrelated conversation]

Tony: I don't know if you've ever seen the NASA ships, but normal一not

ones with any- like flybys or satellite launchers. They are straight

with little tips at the top. That's what I mean.

Upon first sharing a metaphor for the position of his body, when Tony was asked how else to make pink, he possibly internalized that question as meaning another metaphor to represent the position of his arms in relation to his body. Then, his detailed explanation of what he meant by being a rocket demonstrates that he was perfectly aware of his body (thus taking on the bodybased perspective) and was able to make a connection to something that he had seen before in life: a rocket.

Research has suggested that "knowing mathematics, really knowing it, means understanding it". 31 "Understanding" is defined as the ability to see how a concept is related or connected to other things we know. ${ }^{31}$ Tony's astute ability to make connections between his body and objects he had been exposed to created an optimal condition for encompassing the dual perspective in the later stages of the task. Once the arrows were introduced to the screen, Tony had the opportunity to make further connections; except, this time, they were connections between his body and the angle, resulting in the dual perspective. Tony was the only one of the three students who truly encapsulated the dual perspective. Despite not being completely correct with every assertion during the third stage, Tony consistently verbalized the position of his arms in relation to the numerical value of the degrees that changed the screen each color. This proved to be a more challenging connection for other students to make.

\section{DISCUSSION}

The body-based task in this study was designed so that participants could adopt the perspectives in a specific manner that we hypothesized would be conducive to learning. Based upon observation and analysis of the three selected students, it suggests that the body-based task was properly designed to support these participants' transitions through various perspectives. Each of the three students endured Stage 1 with a body-based perspective and then focused on an angle-based perspective during Stage 2 . Once the protractor was introduced, there were some differences in the perspectives each of the three students occupied, yet it was clear that they centered on the perspective that was most salient in their minds. For Tony, the protractor greatly influenced his perspective, as it provoked him to relate the position of his arms to the degree measure of the angle. For Abdul, a student who 
struggled throughout the duration of the task, once the questions were less directed at a certain perspective, he retreated to a body-based perspective. It was clear that he was not grasping the angle concept, and so he felt more at ease with his body.

It seems plausible to expect students to be more comfortable with a body-based perspective; they are already familiar with their bodies, and so they are able to use their bodies to make sense of the world and form complex ideas. ${ }^{9}, 11$ By first prompting participants to consider how their bodies were affecting the angle on the screen, we were narrowing their attention and allowing them to explore an entity that they should have felt quite comfortable with. Perhaps, as evidenced by Abdul's interview, if a student was not able to comprehend the angle concept, then he or she would resort to using a body-based perspective.

Mastering the body is helpful in order for development and learning to occur. ${ }^{32}$ More specifically, whenever students are in the midst of learning mathematics, they are forced to constantly question the physical environment, which facilitates changes in their bodily movements. ${ }^{33}$ The ease with which students make those changes could be related to how deeply they master the new and unknown concept.

Along with establishing a strong body-based perspective early on in the task, the use of metaphors seemed to aid the three students in better understanding the angle concept. Metaphors are a simple way to linguistically describe our bodily interactions with the world. ${ }^{10,34}$ If students genuinely understand a concept, then they are capable of expressing connections between the new idea and previous knowledge, ${ }^{31}$ which can take place in the form of metaphors that relate the body to a concept. In the bodybased task, Tony's metaphors were vivid and frequent, and perhaps, his ability to make connections in the first stage was related to his strength in eventually connecting the movement of his body with the angle measure on the screen. On the contrary, Abdul lacked metaphor in his verbal responses, particularly during the earlier stages, so this potentially became a hindrance on his ability to connect different entities later in the interview.

The results of this study were somewhat limited due to the constraint of only analyzing three students. It would be interesting to consider whether other students whose patterns of perspective-taking closely align with Tony's also demonstrate significant learning gains or students whose patterns model Jace's continue to affirm their previously strong angle concept. Similarly, students whose patterns resemble Abdul's during the body-based task might not achieve learning gains. Furthermore, the case studies featured three male students, so a lack of female representation might affect the patterns of perspective-taking. The three students were initially selected blindly, as only their scores on the assessments were considered for inclusion. Therefore, if a larger size of students were to be selected, including both males and females, the results of this specific analysis might be impacted.

Additionally, increasing the sample size would allow further generalizations to be made about how students interact with and learn from a body-based task.

Since so much of mathematics curriculum and instruction hinges on understanding abstract concepts, it is crucial to be mindful of how students can better grasp complex ideas, like angles. This study has suggested that prompting students to explore abstract concepts in a body-based fashion can promote their development of abstract ideas that become pivotal to truly learning mathematics, beyond procedural computations. It provides grounds for mathematics educators to consider how they are approaching instruction in their classroom, and if they are supporting students' intellectual growth of concepts. Finally, if we accept that a body-based perspective is necessary as a first step towards being able to make connections between physical actions and mental representations, then we can further consider specific patterns of perspective-taking that help students to make meaning of abstract concepts.

\section{ACKNOWLEDGEMENTS}

The author thanks Carmen Smith, an exceptional advisor who has helped in countless ways throughout the entire process of producing this work. Thank you, also, to Barbara King and Diana Gonzales for their contributions and support. 


\section{REFERENCES}

1. Nemirovsky, R., and Ferrara, F. (2009) Mathematical imagination and embodied cognition, Educ Stud Math 70, $159-174$.

2. Johnson-Glenberg, M. C., Birchfield, D. A., Tolentino, L., and Koziupa, T. (2013) Collaborative embodied learning in mixed reality motion-capture environments: Two science studies, J Educ Psychol, 19-30.

3. Nathan, M. J., Walkington, C., Boncoddo, R., Pier, E., Williams, C. C., and Alibali, M. W. (2014) Actions speak louder with words: The role of action and pedagogical language for grounding mathematical proof, Learn Ins 33, $182-193$.

4. Johnson-Glenberg, M., Birchfield, D., Koziupa, T., Savio-Ramos, C., and Cruse, J. (2012) Seeing it Versus Doing it: Lessons from Mixed Reality STEM Education, in Proceedings of the International Conference of the Learning Sciences: Future of Learning (Freedbody, P., de Jong, T., Kyza, E., and Reimann, P., Eds.), 103-104, University of Sydney/ISLS, Sydney.

5. Ackermann, E. K. (1996) Perspective-Taking and Object Construction: Two Keys to Learning, in Constructionism in Practice: Designing, Thinking, and Learning in a Digital World (Kafai, Y. and Resnick, M., Eds.), 25-37, Lawrence Erlbaum Associates, Mahwah, NJ.

6. Petrick, C. J., and Martin, H. T. (2012) Learning Mathematics: You're it vs. it's it, in Proceedings of the International Conference of the Learning Sciences: Future of Learning (Freedbody, P., de Jong, T., Kyza, E., and Reimann, P., Eds.), 101-102, University of Sydney/ISLS, Sydney.

7. Gerofsky, S. (2011) Seeing the Graph vs. Being the Graph: Gesture, Engagement and Awareness in School Mathematics, in Integrating Gestures (Stam, G., and Ishino, M., Eds.), 245-256, John Benjamins, Amsterdam.

8. Smith, C., Berland, M., and Martin, T. (2014) Playing Robot: Exploring how Students Alternate Perspectives in IPRO, in Learning Technologies and the Body: Integration and Implementation in Formal and Informal Learning Environments (Lee, V., Ed.), 132-148, Routledge, New York.

9. Anderson, M. L. (2003) Embodied cognition: A field guide, Artif Intell 149, 91-130.

10. Lakoff, G., and Johnson, M. (1999) Philosophy in the Flesh: The Embodied Mind and its Challenge to Western Thought, Basic Books, New York.

11. Barsalou, L. W. (2008) Grounded cognition, Annu Rev Psychol 59, 617-645.

12. Kirsh, D., Complementary Strategies: Why we use our Hands when we Think, http:/ / adrenaline.ucsd.edu/kirsh/articles/cogsci95/cogsci95.html (accessed Dec 2015).

13. Abrahamson, D., Trninic, D., and Gutierrez, J. F. (2012) You Made it! From Action to Object in Guided Embodied Interaction Design, in Proceedings of the International Conference of the Learning Sciences: Future of Learning (Freedbody, P., de Jong, T., Kyza, E., and Reimann, P., Eds.), 101-102, University of Sydney/ISLS, Sydney.

14. Walkington, C., Srisurichan, R., Nathan, M., Williams, C., Alibali, M., Boncoddo, R., and Pier, L. (2012) Grounding Mathematical Justifications in Concrete Embodied Experience: The Link Between Action and Cognition, in Paper presented at the Annual Meeting of the American Educational Research Association, Vancouver, Canada.

15. Piaget, J. (1952) The Origins of Intelligence in Children, International Universities Press, New York.

16. Lindgren, R., Aakre, A., and Moshell, M. (2012) You're the Asteroid! Body-Based Metaphors in a Mixed Reality Simulation of Planetary Astronomy, in Proceedings of the International Conference of the Learning Sciences: Future of Learning (Freedbody, P., de Jong, T., Kyza, E., and Reimann, P., Eds.), 101-102, University of Sydney/ISLS, Sydney.

17. Byrne, P., and Becker, S. (2008) A principle for learning egocentric-allocentric Transformation, Neural Comp 20, $709-737$.

18. Mitchelmore, M. C., and White, P. (2000) Development of angle concepts by progressive abstraction and generalization, Educ Stud Math 41, 209-238.

19. Thompson, P.W. (2008) Conceptual Analysis of Mathematical Ideas: Some Spadework at the Foundation of Mathematics Education, in Proceedings of the 32nd Annual Conference of the International Group for the Psychology of Mathematics Education (Figueras, O., Cortina, J. L., Alatorre, S., Rojano, T., and Sepulveda, A., Eds.), 45-64, Morelia, Mexico.

20. Douek, N. (1998) Analysis of a Long Term Construction of the Angle Concept in the Field of Experience of Sunshadows, in Proceedings of the 20th Annual Conference of the International Group for the Psychology of Mathematics Education (Olivier, A., and Newstead, K., Eds.), 264-271. Stellenbosh.

21. Mitchelmore, M. C., and White, P. (1998) Development of angle concepts: A framework for research, Math Educ Res J 10, 427.

22. Clements, D. (2003) Teaching and Learning in Geometry, in A Research Companion to Principles and Standards for School Mathematics (Kilpatrick, J., Martin, W. G., and Schifter, D., Eds.), 151-178, National Council of Teachers of Mathematics, Reston, VA.

23. Goldin, G. (2000). A Scientific Perspective on Structured, Task-Based interviews in Mathematics Education Research, in Handbook of Research Design in Mathematics and Science Education (Kelly, A., and Lesh, R., Eds.), 517-545, Lawrence Erlbaum Associates, Mahwah, NJ.

24. Patton, M. (2002) Qualitative Research and Evaluative Methods, Sage Publications, Thousand Oaks, CA.

25. Yin, R. (2013) Case Study Research: Design and Methods, Sage Publications, Thousand Oaks, CA.

26. Smith, C., King, B., Gonzalez, D., and Paul, N. (2015) The Role of Action in the Development of Angle Concepts, paper presented at the annual meeting of the American Educational Research Association, Chicago. 
27. Glesne, C. (2010) Becoming Qualitative Researchers: An Introduction, Pearson, Boston.

28. Ochs, E., Gonzalez, P., and Jacoby, S. (1996) "When I Come Down I'm in the Domain State": Grammar and Graphic Representation in the Interpretive Activity of Physics, in Interaction and Grammar (Ochs, E., Schegloff, E., and Thompson, S., Eds.), 328-369, Cambridge University Press, Cambridge.

29. Miles, M. B., and Huberman, A. M. (1994) Qualitative Data Analysis, Sage Publications, Thousand Oaks, CA.

30. McNeill, D. (1996) Hand and Mind: What Gestures Reveal About Thought, The University of Chicago Press, Chicago.

31. Hiebert, J., Carpenter, T. P., Fennema, E., Fuson, K. C., Wearne, D., Murray, H., Olivier, A., and Human, P. (2000) Making Sense: Teaching and Learning Mathematics with Understanding, Heinemann, Portsmouth, NH.

32. Dewey, J. (1998) How We Think: A Restatement of the Relation of Reflective Thinking to the Educative Process, Houghton Mifflin Company, Boston.

33. Nemirovsky, R., Borba, M., and Dimattia, C. (2004) PME Special Issue: Bodily activity and imagination in mathematics learning, Educ Stud Math 57, 303-321.

34. Gibbs Jr., R. W., Lima, P. L. C., and Francozo, E. (2004) Metaphor is grounded in embodied experience, J Pragmat 36, 1189 1210.

\section{ABOUT THE STUDENT AUTHOR}

Tegan Garon recently graduated from the University of Vermont with a B.S. in Education, in addition to earning his Vermont teaching license for mathematics, grades 7-12. He graduated from the Honors College, in which his senior thesis evolved into this article. He will be teaching mathematics at a Vermont high school in the upcoming school year.

\section{PRESS SUMMARY}

While students are learning mathematical concepts, such as angles, the movements of their bodies support their learning. As students undergo this learning process, they may assume various perspectives, namely a first-person perspective, where they take on the role of the mathematical object, and a third-person perspective, where they perceive themselves as an observer of the task. Students' abilities to fluctuate between these perspectives can have significant effects on their learning gains. 


\section{APPENDIX}

These questions were used for the administration of an identical pre-test and post-test.

1. Draw an angle. Now draw an angle that is different from the first one you drew.

2. Draw an angle that is bigger than this angle.

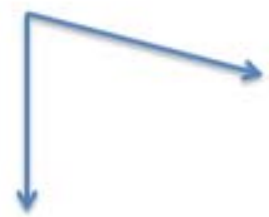

3. Draw an angle that is smaller than this angle.

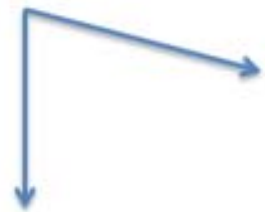

4. Draw an angle that is 90 degrees.

5. Draw an angle that is 30 degrees.

6. Draw an angle that is 150 degrees.

7. Draw an angle that is 180 degrees.

8. Estimate the size of this angle.

$\leftarrow$

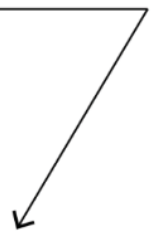

9. Estimate the size of this angle.

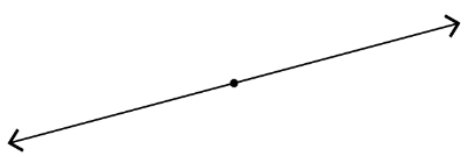

10. Estimate the size of this angle.

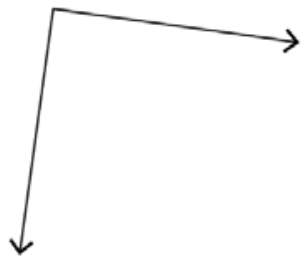

11. Estimate the size of this angle.

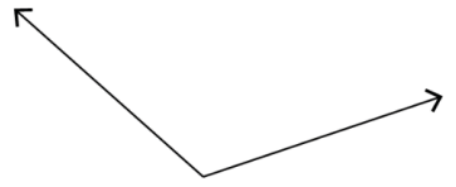

